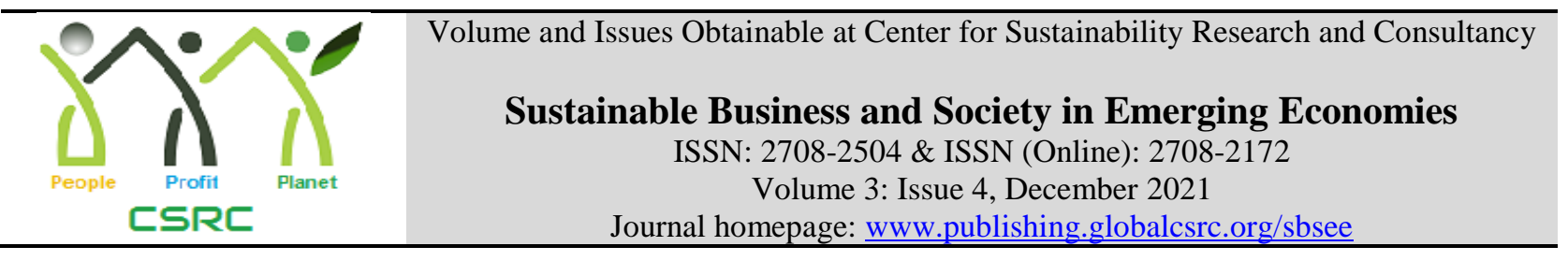

\title{
Usage of Facebook an Inspiration or a Distraction for Students on their Academic Performance
}

Ramish Mufti, Lahore Institute of Science and Technology, Lahore, Pakistan Mariam Saleem, Lahore Institute of Science and Technology, Lahore, Pakistan Abdul Basit, Lahore Institute of Science and Technology, Lahore, Pakistan

Corresponding author's Email: abasit_shahbaz@yahoo.com

\begin{tabular}{l}
\hline ARTICLE DETAILS \\
\hline History \\
Revised format: Nov 2021 \\
Available Online: Dec 2021 \\
\hline Keywords \\
Social Network Sites, \\
Facebook, Behavioral \\
Change, Students' \\
Academic Performance, \\
Pakistan
\end{tabular}

JEL Classification A20, A29

\section{ABSTRACT}

Purpose: It has been observed that social networking sites especially Facebook is affecting the performance of the students. The purpose of this paper is to explore and study the experiences of students with Facebook on their academic performance.

Design/methodology/approach: Qualitative research methodology is used as it sheds light on the experiences of people involved and makes an attempt to understand the reasons behind certain behavioral change. The students of undergraduate program of various departments of different private and public academic institutions are taken in account for this research study. Based on the extensive review of literature, semi-structured interviews were conducted for data collection.

Findings: Data gathered from the interviews have clearly indicated the adverse effect of Facebook on students' academic performance which can be seen in the interview excerpts of different students. Review of literature also indicates that the overwhelming usage of Facebook is creating silo walls that isolate people from family, friends and society.

Practical Implications: The study provides the guidance to teachers, academicians, educationists, researchers, regulators, parents and students for change in pattern of behavior and its consequences on students' academic performance. Furthermore, the study brings awareness among undergraduate students about how Facebook affects their academic performance.

Originality/Value: This study is among few studies that thoroughly explore and describe the devastating impact of overwhelm use of Facebook on students' academic performance.

(C) 2021 The authors, under a Creative Commons AttributionNonCommercial 4.0

Recommended citation: Mufti, R. Saleem, M. and Basit, A. (2021). Usage of Facebook an Inspiration or a Distraction for Students on their Academic Performance. Sustainable Business and Society in Emerging Economies, 3(4), 521-529.

\section{Introduction}

Accelerating technological advancements in Information and Communication Technologies 
(ICTs) has prodigious influence on individuals, society and organizations (Murad et al., 2019). In the recent years, the use of Social Networking Sites (SNSs) especially Facebook has greatly increased and has both positive and negative effects on students (Karpinski \& Duberstein, 2009; Rouis et al., 2011). Almost everyone knows, 19 years old sophomore Harvard student named Mark Zukerberg developed this revolutionary site in February 4, 2004 to connect Harvard University students. Later, it was redesigned for connecting people around the world. According to Statista, over 2.89 billion active users have been using it as of November, 2021. Today, majority of Facebook users are students who are actively using the application to share photos \& information, communicate with friends and relatives using Facebook messenger (Putri \& Aminatun, 2021). It is really hard to find someone who is not using Facebook. It becomes the second skin of teens. Facebook helps to strengthen the relationship of people. However, some research articles state that it is also a reason for isolating the people from the society since they reduce the face-to-face socialization and also affects the academic performance of the students (Rouis et al., 2011). Young people are wasting most of their time in Facebook and sometimes it even ruins human lives. There have been several researches conducted to examine the impact of Facebook which has explored both positive and negatives effects on people (Vasalou et al., 2010). However, the fast-developing technological advancements and widely used technical artifacts such as smart phones and laptops are highly attracting the people due to which the number of users using the Facebook has been rapidly increasing every day. People are able to communicate instantly, share their information, emotions and feelings with the help of Facebook in the geographically separated world and conversely it is deteriorating the students' academic performance Błachnio \& Przepiorka, 2019; Busalim et al., 2019. When the number of users increases, a new pattern can be seen in both positive and negative aspects. Hence, it is essential to examine the impact of Facebook on the behavior of students towards their study by conducting a research (Habes et al., 2021).

\section{Problem Area}

Rapid changes and use of technologies have both fortunate and adverse effect on students and society as a whole (Mosquera et al., 2020). ICT has changed the human qualities such as: social competence, dependency, identity \& self-perception, creativity, trust, integrity and vulnerability (Bradley, 2010). Mingers and Willcocks (2004) argued that technologies transform our experience of the world and our perceptions and interpretations of our world, and we in turn become transformed in this process. Technical artifacts such as Facebook, smart phones and computers change the individual's behavior and how these changing patterns affect the students' academic performance which also reflects in society remains largely unanswered (Ley et al. 2014). Therefore, the research is conducted to answer the following research questions:

RQ1: What is the influence of Facebook on students; constructive influence or destructive influence?

$R Q 2$ : Does Facebook usage has any association to the students' academic performance?

$R Q 3$ : What are the experiences of students who use Facebook excessively?

\section{Scope of Study and Settings}

Youngsters are the backbone for the development of a country. Since the inception of SNSs, these have been contributing in learning process by integrating students, teachers and others people (Awidi et al., 2019). However, last couple of years it has been observed that SNSs especially Facebook have been hampering academic, personal, and social life of students (Murad et al., 2019). This study has been conducted to find out how Facebook is influencing positively or negatively on the academic performance of students. For conducting this research, private and public academic institutions have been chosen with multicultural background. So the participants for conducting research are students from undergraduate program. Research is conducted during 
the institutions working days since the students are available at the campus. Rest of the papers is structure as: literature review, theoretical framework, methodology, data analysis, discussion and conclusion.

\section{Literature Review}

Technologies are fortune for students to fetch desire information for their academic purpose. Since the smart phones and internet has become unavoidable part of human lives, students easily get tempted to use social media which easily distract them from academic studies. Technological advancements and innovations have always been a topic of debate among the researchers regarding the blessings and adversaries for human beings and same is the case with the development of SNSs (Feng et al., 2019). Several studies have been conducted to pinpoint and highlights both bright and dark aspects of these SNSs on their users (Rouis et al., 2013; Vasalou et al., 2010). Among all the SNSs, Facebook is one of the most popular and recognized platform used on the internet (Putri \& Aminatun, 2021). The data bases of Web of Science, Scopus, Emerald, EBSCO, Taylor \& Francis, Science Direct and Wiley-Blackwell were rigorously searched to evaluate the published research using key words: social network sites, SNS, Facebook, academic performance, students' academic performance, usage of Facebook, Facebook addiction, usefulness of Facebook, etc. Different context research papers, conference papers, working papers and book chapters were also found, which were excluded from the study and few of them are being reported here with brevity. Before embark to evaluate the core literature, it is pertinent to present the efforts made by different researchers relevant to study in hand to set the context of the study viz: It is evident that technology can have an influential role and adverse impact in changing the individuals' behaviors or adopting desirable behaviors (Elliot, 2011). Economic condition, living standard, societal change, common pattern of behavior largely depends upon the technology and its exploitation. Melville (2010) claimed that information systems play a pivotal role in acquisition of information and formation of attitude. Technology has the ability to shape the world that result in changing the values of the individuals and society (Radovan, 2013). The usage of technology increases the generation gap between the young and old people. The invention in technology influences in changing behavior process that results in environmentally desirable behaviors (Elliot, 2011). Verbreek (2006) found that technologies profoundly influence the behavior and experience of users. Su and Chen (2020) argued that learning performance of the students who are using Facebook is more than those who are not using Facebook because Facebook users are socially linked with people and their daily discussion enhanced their knowledge. Moorthy et al. (2019) asserted that Facebook offered a new medium of learning to distance learners and also user friendly application for online discussions. Barrot (2021) claimed that Facebook is a beneficial medium for exchange of information due to its interactive features, flexibility and accessibility. Similarly, Lai et al. (2108) buttressed that Facebook has positively impact on the subjective well-being of both male and female students. Raza et al. (2020) highlighted that perceived behavior control, communal impact, attitude and information seeking have a constructive and substantial impact on Facebook usage among the students. They further proclaimed that folks are more ambitious to use Facebook to make their social circle stronger, cram new ideas and use it as information-seekers. Błachnio and Przepiorka (2019) bolstered that the excessive use of Facebook ultimately leads to phubbing attitude in users. Frist they feel loneliness later on it converted in to phubbing behaviors. Busalim et al. (2019) found that habitual students change statistically in self-esteem from non-addicted ones. Likewise, Facebook addiction has substantial consequence on students' educational performance. Their study outcomes also provide a healthier understanding of selfesteem element that meaningfully effect on student's Facebook addiction and educational performance. Rajesh and Rangaiah (2020) concluded that extreme use of Facebook has harmful effect on student's personality resultantly they feel alone and depressed. Feng et al. (2019) affirmed that use of social applications such as Facebook has become the source of distractions in students' academic life. Crisp of literature has provided the background to embark on 
developing the theoretical framework to analyze the phenomenon under study.

\section{Theoretical Framework}

Students find Facebook as addiction that whenever they are studying they unintentionally start using Facebook. It leads to do them multitasking and loses focus of one task which can be a cause of poor performance. According to the cognitive load theory, cognitive resources are being used in every cognitive processing activity in task of learning and problem solving (Sweller, 2011). The study further explained that when a person uses access resources and total required resources on all activities exceed the affordable human range, the cognitive overload occurs which is due to insufficient resources allocated to one task. This shows that multitasking leads to poor performance. In this study, when students are aggressively using Facebook while studying, their focus is divided which leads to have a bad end result on their academic performance (Feng et al., 2019). Facebook has the global popularity and it has become a need of every person to stay connected. In Maslow's hierarchy of needs, the third need which is the social need explains that the social stage is an important part of psychological development because our relationships are now dependent on these social media applications. Usage of Facebook has become a need but over usage can divert the focus of students (Ferrell, 2011; Rajesh \& Rangaiah, 2020; Su \& Chen, 2021). Baron in 1986 suggested in his distraction-conflict theory that attention conflict can occur if there is distraction from a particular task. Distraction has variety of effects on cognition, attitude change and social behavior. Facebook users have become addicted to open Facebook every now and then which leads to have less focus on their studies, hence affecting the academic performance of the students.

\section{Methodology}

Qualitative research approach was used to study the experiences of the students and to understand the behavior of the students from the academic institutions at undergraduate level. The design of the study was descriptive and exploratory. Personal views and experiences of the students were taken in account. The population of the study was public and private academic institutions of Lahore, Pakistan which are offering undergraduate programs. Undergraduate programs are considered to be the most vulnerable for using Facebook as being naïve they find difficulty to control themselves from the over usage of Facebook. Non-probability purposive sampling was used as sampling strategy to reach the targeted participants. The sample size in qualitative research is taken until the saturation point was achieved by the researcher. Therefore, total 20 interviews were conducted from the students of different departments of the institutes. The institutes were from the private and public sectors. From public sector, interviews were conducted from different departments of University of the Punjab including: Institute of Business Administration (IBA), Institute of Administrative Sciences (IAS) and Institute of Business and Information Technology (IBIT). From private sector, interviews were conducted from Superior University, University of South Asia and Lahore Institute of Science \& Technology (LIST). Respondents were 18 years to 22 years of age, consisting of 10 male and 10 female each. Interview guide was prepared beforehand in accordance with the aim and research questions to conduct in depth interviews. While conducting the interviews, the probes were being asked during the interviews as it was a semi-structured interview guide. Further probing was done from the students to get the detailed insight of the experience they have with Facebook. Permission was taken from the participants to recording their interviews for the transcription process. 30 students were approached for data collection and 20 interviews were conducted from the students who were willing. Out of which 15 interviews were considered appropriate and remaining interviews were discarded having the issue of being properly audible to understand the responses for transcription. The audio-taped interviews were transcribed using the approach of verbatim. For analysis purpose, different open codes were generated. On the basis of the codes, the categories were developed that led towards broader qualitative themes which was depicting the major findings of the research study. While analyzing the data, it was the main concern that the 
researchers' opinion do not create any biasness. The privacy of the participants were also taken into account so that any data of the respondent is kept private and not used for any other purpose other than the research in hand. It took around 2 months to collect and analyze the data.

\section{Data Analysis}

For carefully analyzing the data, thematic analysis technique was chosen and open codes were extracted from the transcription of the interviews. Then they were categorized into the main themes. Three major broad themes were emerged and those were further divided into the subthemes:

\section{Facebook as a Learning Tool}

\section{Experiences of Students with Facebook for their Academic Activities}

The participants of this study were being asked about their experience with Facebook that whether it's a useful tool for their academic activities. Almost all the participants were having the same view that they do not use Facebook for their studies. They said that we just want to share our life updates and just want to check what is happening and what statuses are being shared. One of the respondents shared her view:

"Facebook is just for check - ins. I don't find any academic activities happening on Facebook." R2

\section{Progression through Facebook}

Participants were also interrogated about whether they are making any progress and success by using Facebook and it has helped them in achieving some goals or they are getting any kind of motivation from Facebook. Furthermore, they were also being probed that they spent a lot of time on Facebook, so do they get any guidance related to their career? Almost 18 of the respondents answered the question in negative that Facebook is just for entertainment. We do not see anything related to career, in fact whatever is being showed on Facebook is mostly fake. The interview excerpt of one of the respondents clearly shows that they have security issues so don't believe on what is being portrayed on Facebook.

"People mostly show off on Facebook, everything on Facebook is just for fun sake. Nobody in my circle has shared anything that they do anything related to studies on Facebook" RI

So, it can be seen from the responses that mostly students are not having any awareness that Facebook can also be used positively and it has its uses as well. Rather they think it consumes their time a lot and they don't gain anything from it. Even they are scolded from their parents as well that stop wasting your time on Facebook. Facebook term is mostly use in negative connotation in Pakistani culture.

\section{Facebook a Social Connection Hub Social Need of this Era}

Experiences and views from all the students were like that Facebook now is a necessity and how can someone survive without Facebook. Even when they get to know somebody is not having a Facebook account, they do try to make fun of that person and also humiliate him or her. Facebook makes people update with latest trend/fashion and connected in the different parts of the world. People put their life achievements and life updates on Facebook. One of the respondents explained:

"I think that putting everything on Facebook is like invading anyone's privacy. People start comparing their lives with others' lives. I am not in the favor of putting everything on Facebook. It fine to stay connected but these life updates can be depressing for some people. " R5 
Also one of the respondents shared that:

"We get to know all the latest trends of fashion from Facebook and we can become friends with people from abroad." R13

\section{Easy Communication}

Almost all of the participants agreed that Facebook is a source of communication and it is a platform where everyone stay connected, even if they are not talking on phone or personally meeting them. They can communicate with their classmates and teachers on Facebook. It is a major source of enjoyment and chatting and getting to know the people which are not approachable. Mostly said yes this platform is used for non-academic purposes.

One of the participants told:

"I found my long lost childhood friend on Facebook from a different city and now we are connected just because of Facebook" R7

Students from various institutes proclaimed that Facebook is connecting people around the globe. Everyone knows what is happening in other person's life just because of a Facebook status or a check in. Students express their views that they are so fascinated with this Facebook world that they want to put everything on Facebook.

\section{Facebook a Major Source of Distraction Feeling of Addiction}

When the participants were being asked about why they use Facebook and they were being interviewed about their academic performance that whether Facebook is a helping tool for their studies. Almost all of the participants shared that no it doesn't help them in their studies, rather they feel addicted to it. Students said that even if they are on the eating table, studying or in the washroom they are just scrolling the Facebook. This addiction is so bad and they cannot taper that off. It's hard for them to stop themselves using the Facebook.

From many of the interview excerpts this can be seen:

"I waste a lot of time on Facebook, even I know that I am wasting time but still I have to open Facebook and scroll it, especially when I am studying. I use Facebook multiple times for no reason, just watches silly funny videos and share memes related to exams and the student life." R19

Another respondent shared:

"I really wish to stop using Facebook when I am studying, but I can't help it. I have become habitual of using Facebook." R20

Attention Diverter Participants also shared their views that we lose focus when all of a sudden we start using Facebook. It has nothing to do with our studies, it's just we waste our time and energy. It seems from the experiences of students that even if they want to study and focus, their attention is diverted towards Facebook unintentionally and automatically because they have become so addicted to it. Most of the time, it causes poor academic performance. Excess of everything is bad and over usage of social media sites leads to diverting their focus from studies.

One of the respondents answered:

"Yes I need to stop using Facebook, I deactivate Facebook when my exams are near, because I keep opening it for no good reason." $R 8$

\section{Discussion}

Facebook has become a very addictive entertainment among the youngsters. The main purpose of this study was to explore and study the experiences of students with Facebook on their 
academic performance. The findings of the study show that Facebook is majorly a source of distraction for students who have just entered in their university life. However, finding of the study are not showing the relevance with some of the prior studies (Barrot, 2021; Lai et al., 2108; Niu, 2019; Su \& Chen, 2020) as it is being used as a learning tool for their academic purpose (Kaso et al., 2021). Similarly, Niu (2019) revealed that usage of Facebook has positive effect in academia but he further argued that Facebook is not suitable medium in all academic discipline and there is a need to explore more information regarding to usage of Facebook in academic sector. Keeping in mind the population of this study was from undergraduate level and less developed nation, these students have relatively less awareness to use Facebook as a positive tool. Being naïve, they find difficulty to control themselves from the over usage of Facebook. They are socially influenced with Facebook entertainment at the cost of decreasing their grades in the studies (Feng el al., 2019; Fewkes \& McCabe, 2012). This paper concludes from the lived experiences of the students which find change in the behavior resultantly distracting them and hence upsetting their academic performance. The findings of the study is aligned with previous studies (Błachnio \& Przepiorka, 2019; Busalim et al., 2019; Ley et al., 2014; Rajesh \& Rangaiah, 2020; Su \& Chen, 2021).

\section{Conclusion}

ICT has changed the lifestyle of the humans. It has been observed that technology has completely transformed the society and the way people behave and act in society. It is important to not only understand the humans-computer relationship but also devise some strategies to manage their relationship. Tremendous advancement of mobile telecommunication platform and development of SNSs are major contribution of IT. SNSs especially Facebook with the help of Internet and ubiquitous technology has pushed forward the communication platform to new stage. Facebook itself connects more than 2.8 billion people around the world. Through Facebook, people easily communicate a large number of people, share their ideas and feelings. Facebook has created virtual society for people. Besides of these advantages, Facebook also brings a lot of disadvantages especially for the students. Findings of the study conclude that it isolates people from family, friends and society. It is very common to notice that students are using Facebook in class room, in library while studying, on dining table, on street and even while they are gossiping with their friends. Surfing in Facebook has become a common and very popular pass time for students. Now question is "What are the disadvantages of passing so much time on Facebook for students' academic performance?" It has been observed that Facebook hamper academic performance of students by wasting so much valuable time on Facebook and it has become an addiction for many students. Many students spend more time on Facebook rather than study. Surfing on Facebook during study seriously distracts student from study. Facebook itself is not threat for students but it becomes a threat when students waste a lot of valuable time doing unproductive things rather than study. Students should use Facebook as communication media to connect and communicate with other people and share their ideas rather than just passing time. There have been several research studies conducted to examine the positive and adverse effects of Facebook. However, there are more chances that the results might vary due to the factors such as technological advancements, use of new applications, increase in the number people who are using the Facebook, behavioral changes of people, etc. These are some of the reasons to conduct this research to find out its influence. As this study is conducted in Pakistani institutions, the generalizability is limited to Pakistani institutions and cannot be applied to other country's institutions without a further validation. There are certain implications of the study. It is anticipated that the outcomes would add valuable knowledge into existing body of knowledge and it would be beneficial for teachers, academicians, educationists, researchers, regulators and parents. Furthermore, the study brings awareness among undergraduate students about how Facebook affects their academic performance. 


\section{References}

Awidi, I. T., Paynter, M., \& Vujosevic, T. (2019). Facebook group in the learning design of a higher education course: An analysis of factors influencing positive learning experience for students. Computers \& Education, 129, 106-121.

Baron, R. S. (1986). Distraction-conflict theory: Progress and problems. Advances in experimental social psychology, 19, 1-40.

Barrot, J. S. (2021). Effects of Facebook-based e-portfolio on ESL learners' writing performance. Language, Culture and Curriculum, 34(1), 95-111.

Błachnio, A., \& Przepiorka, A. (2019). Be aware! If you start using Facebook problematically you will feel lonely: Phubbing, loneliness, self-esteem, and Facebook intrusion. A crosssectional study. Social Science Computer Review, 37(2), 270-278.

Bradley, G. (2010). The Convergence Theory on ICT, Society and Human Beings - towards the Good ICT society. TripleC, 8(2), 182-192.

Busalim, A. H., Masrom, M., \& Zakaria, W. N. B. W. (2019). The impact of Facebook addiction and self-esteem on students' academic performance: A multi-group analysis. Computers \& Education, 142, 103651.

Elliot, S. (2011). Trans disciplinary perspectives on environmental sustainability: A resource base and framework for it-enabled business transformation. MIS Quarterly, 35(1), 197-236.

Feng, S., Wong, Y. K., Wong, L. Y., \& Hossain, L. (2019). The Internet and Facebook usage on academic distraction of college students. Computers \& Education, 134, 41-49.

Ferrell, J. D. (2011). A functional role of Facebook: Psychological and social needs. University of Central Oklahoma.

Fewkes, A. M., \& McCabe, M. (2012). Facebook: learning tool or distraction?. Journal of Digital Learning in Teacher Education, 28(3), 92-98.

Habes, M., Alghizzawi, M., Salloum, S. A., \& Mhamdi, C. (2021). Effects of Facebook personal news sharing on building social capital in Jordanian universities. In Recent Advances in Intelligent Systems and Smart Applications (pp. 653-670). Springer, Cham.

Karpinski, A. C., \& Duberstein, A. (2009).A description of Facebook use and academic performance among undergraduate and graduate students. American Educational Research Association (AERA) Conference, San Diego, 13-17 April.

Kaso, N., Nurjihad, A., Ilham, D., \& Aswar, N. (2021). Facebook and its Impact on Students' Learning Achievement at State Islamic High School of Palopo. JurnalStudi Guru danPembelajaran, 4(1), 1-15.

Lai, H. M., Hsieh, P. J., \& Zhang, R. C. (2019). Understanding adolescent students' use of Facebook and their subjective wellbeing: a gender-based comparison. Behaviour \& Information Technology, 38(5), 533-548.

Ley, B., Ogonowski, C., Hess, J., Reichling, T., Wan, L., \& Wulf V. (2014). Impacts of new technologies on media usage and social behavior in domestic environments. Behavior and Information Technology, 33(8), 815-828.

Melville, N. (2010). Information systems innovation for environmental sustainability. MIS Quarterly, 34(1), 1-21.

Mingers, J., \& Willcocks, L. (eds.) (2004). Social theory and philosophy for information Systems. Chichester, UK: Wiley.

Moorthy, K., T'ing, L. C., Wei, K. M., Mei, P. T. Z., Yee, C. Y., Wern, K. L. J., \& Xin, Y. M. (2019). Is facebook useful for learning? A study in private universities in Malaysia. Computers \& Education, 130, 94-104.

Mosquera, R., Odunowo, M., McNamara, T., Guo, X., \& Petrie, R. (2020). The economic effects of Facebook. Experimental Economics, 23(2), 575-602.

Murad, A., Gul, A., Changezi, R., Naz, A., \& Khan, N. (2019). Effects of Facebook usage on the academic performance on the undergraduate students of Quetta City. CLINICAL SOCIAL WORK, 70 . 
Niu, L. (2019). Using Facebook for academic purposes: Current literature and directions for future research. Journal of Educational Computing Research, 56(8), 1384-1406.

Putri, N., \& Aminatun, D. (2021). Using Facebook to practice writing skill: what do the students think?. Journal of English Language Teaching and Learning, 2(1), 45-50.

Radovan, M. (2013). ICT and Human Progress. The Information Society, 29(1), 297-306.

Rajesh, T., \& Rangaiah, B. (2020). Facebook addiction and personality. Heliyon, 6(1), e03184.

Raza, S. A., Qazi, W., Shah, N., Qureshi, M. A., Qaiser, S., \& Ali, R. (2020). Drivers of intensive Facebook usage among university students: an implications of U\&G and TPB theories. Technology in Society, 62, 101331.

Rouis, S., Limayem, M., \& Salehi-Sangari, E. (2011). Impact of Facebook Usage on Students' Academic Achievement: Role of Self-Regulation and Trust. Electronic Journal of Research in Educational Psychology, 9(3), 961-994.

Statista, (2021). https://www.statista.com/statistics/264810/number-of-monthly-active-facebookusers-worldwide/

Su, Y. S., \& Chen, H. R. (2020). Social Facebook with big six approaches for improved students' learning performance and behavior: A case study of a project innovation and implementation course. Frontiers in Psychology, 11, 1166.

Sweller, J. (2011). Cognitive load theory. In Psychology of learning and motivation (Vol. 55, pp. 37-76). Academic Press.

Vasalou, A., Joinson, A. N., \& Courvoisier, D. (2010). Cultural differences, experiences with social networks and the nature of "true commitment" in Facebook. International Journal of Human-Computer Studies, 68(10), 719-728.

Verbeek, P. (2006). Materializing Morality:Design Ethics and Technological Mediation. Science, Technology and Human Values, 31(3), 361-380. 